\title{
Non-Chemically Modified Prefix Substance as A Fat Liquor for Leather Manufacture from Recovered Neatsfoot Oil
}

\author{
M. A. Habib \\ Chemistry of Tanning Materials and Leather Technology Department, National \\ Research Centre, P.O. 12622 Dokki, Giza, Egypt and Department of Chemistry, \\ Science College, Al Imam Mohammad Ibn Saud Islamic University (IMSIU), P.O. \\ 90950 (11623), Riyadh, KSA
}

\begin{abstract}
$\mathbf{T}$ HE STUDY is an attempt to provide an economic prefix substance for leather manufacture. An economic and straightforward method has been applied to recover neatsfoot oil from abundant low-cost byproduct (local massacres byproducts). Leather lubricant agent with extra lubricating power has been formulated from the recovered crude oil without chemical modification or further chemical treatment, using a commercial anionic surfactant. It was found that the highest emulsion stability of the formulated lubricants against $\mathrm{pH}$ variation and sundry factors involved in leather tanning has been verified at $30-40 \%$ oil concentration with $2-4 \%$ anionic surfactants as an emulsifier, at $500 \mathrm{rpm}$ stirring speed. Different emulsion concentrations (2-10\%) of the formulated lubricant has been tested as lubricant agent for wet blue leather. The emulsions concentration of $8 \%$ and $10 \%$ formulated lubricant were able to add the required quantity fatty matter to the lubricated leather fiber $(9.12 \%$ and $9.89 \%$ respectively ,based on the weight of lubricated leather ). These ratios are close to that was added by the commercial lubricant at the same concentration. The lubrication process enhances high-performance power and good lubricant effect. The highest values of tensile strength and elongation at break of lubricated leather have been reached at $10 \%$ emulsion concentration, nearly similar to the effect developed by the commercial lubricant. The microscopic examination of the lubricated leather shows that the leather fiber is genuinely coated with a thin film of fat and the perspective of the lubricated leather surface was superior. In addition, the lubricated leather was ostensibly amended.
\end{abstract}

Key words: Neats foot oil, Recycling, Leather, Lubricating agent

\section{Introduction}

In the last years, the rapid development in the meat package technology creates a problem of growing slaughter house wastes. It follows a steady increase in the bio-wastes [1]. The slaughter houses daily pump huge amounts of wet bio-wastes. In the low developing countries these wastes are not well exploited due to lack of recycling facilities. In particular, the solid wastes face many challenges for recycling in the food industry. The most important of which are health caveats and undesirable taste. Unfortunately, they are a congruous medium for microorganism magnification and pathogens zones [2]. Some studies estimate the by-products of pigs and lambs to be $52.0 \%$ and $66.0 \%$, respectively (based on the weight of living animal). This ratio increases to reach $68.0 \%$ in case of cattle [3]. According to Russ and Pittroff, hazard and aspects pollution of meat industry byproducts have a great potential for recycling and conversion into value add products [4]. Some studies have estimated that one ton of killing live bovines generates $275 \mathrm{~kg}$ solid wastes which represent $27.5 \%$ of the total animal weight [3]. Bone represents $15 \%$ of the beef carcasses, $16.5 \%$ of lamb carcasses and $11 \%$ of pork and the marrow represents $4-6 \%$ of total byproduct carcass 
weight [5]. The flimsy feet and legs of animals are adapted to bear the lowering in temperature than the rest of animal body via the heat exchange in the legs between warm cooler venous and arterial. This competitive advantage of neatsfoot oil over the rest of the animal oils attributed to retain the status of liquidity at room temperature. The raw oil is classified as nondrying oil, allows it to easily drench into leather fibers [6]. Therefore, the oil can be used as lubricatingagent. The stiff tanned leather has to recover its durability. The removed fat during beam house operation has to be replaced via a process of lubricating. The process is achieved by emulsification of the oil in an aqueous solution via chemical treatment [7]. The process works to greatly improve the tensile strength and elongation at breaks. Furthermore, the leather fibers adhesion is reduced; consequently, the desired mechanical properties are developed [8]. Vegetable oils and animal fats are the main raw materials have been used as bio-based leather lubricants [9]. Sulfonated oils and fats were an important type in the field. Cottonseed, flax, olive and soya oil are the common vegetable oils used [10-12]. The common sulfonated animal oils that used in leather lubrication are cod liver, sperm, and various fish oils rather than animal fats. Regarding its non-drying oil properties, the crude neatsfootoil was the first prefix used in primitive tanneries on a small scale as a lubricant. Nowadays, the use of the crude oil is useless due to the high prices and lack of abundance. The main problem is that crude oil causes an oily texture and leads to the formation of oily patches on the surface of the skin leading to bring insects. In addition, the traditional use of the untreated oil causes darkness and oil spew on the leather surface. On the other hand, the chemical modification such as sulfonation involves some difficulties among of them the need to use nonecofriendly mineral acids, no mention to times, efforts, and expensive cost. In this work, we try to provide an economic and eco-friendly lubricating agent with a considerable quality via recovery of neatsfoot oil from massacres by-products.It has been achieved to utilize the oil without chemical modification using an anionic surfactant. We are concerned with the feet with no hooves and lower leg bones of sheep, goats and camels. In the municipal massacres, the techniques to collect and recycle them are not available. They are thrown into the garbage. The recovered oil emulsion will be evaluated as well as studying the utilization of the oil as a leather lubricant. The lubricant emulsion stability will be investigated rather than the microscopic appearance and mechanical properties of lubricated leather.

\section{Materials}

Scraps animal legs bone and feet with no hooves of sheep, goats and camels were collected from local municipal abattoir. Chrome tanned leather (wet blue) with a thickness of 2-4 mm feeds from the local medium tannery. Liposol BSFR - anionic fatliquoring agent based on alkanesulfonate, synthetic oils and emulsifiers, technical product. Schill\&sei lecher (Germany). All of the chemicals and reagents used in the work are fine grade feeds from international companies (Merck, Germany, and BDH, England).

\section{Methods}

\section{Neatsfoot oil recovery}

About $5 \mathrm{~kg}$ of legs bone and feet with no hooves were taken and soaked into running water for several times to get rid of impurities and dirts. The bones and feet were then mechanically milled to relatively small parts. The milled materials were then charged to a closed stainless steel reactor and submerged in a double water weight. The mixture was heated to $130^{\circ} \mathrm{C}$ under a reduced pressure up to 90 minutes to obtain the soup. The contents of the reactor were settled down. After that, the soup was transferred to another stainless steel vessel and allowed to cool to room temperature. The upper oily layer was separated by the scrape of, and collected in a dry vessel. The weight of recovered oil was determined and the oil was stored in the clean container.

\section{Recovered neats foot oil analysis}

Crude oil was subjected to chemical and physical analysis according to the American Oil Chemists Society, AOCS 1998 [13,14]. Acid value peroxide value, saponification value, iodine value, unsaponified matters and peroxide value were measured.

\section{lubricants formulation}

For the search, different lubricant samples were prepared depending on the ratios of crude oil and water in different proportions of the anionic surfactant (Liposol BSFR) at fixed stirring speed $(500 \mathrm{rpm})$. The ingredients of differently formulated lubricant samples are shown in Table 1. The samples were prepared on a pilot scale in a stainless steel container prepared with mechanical stirring rods. The weight of each formulated emulsion sample was $500 \mathrm{~g}$. 
TABLE 1 . Ingredients of formulated lubricant samples

\begin{tabular}{cccc}
\hline \multirow{2}{*}{ Sample } & \multicolumn{3}{c}{ Ingredients \% } \\
\cline { 2 - 4 } & crude oil & water & Liposol BSFR \\
\hline $\mathrm{F}_{1}$ & 10.00 & 90.00 & 0.50 \\
$\mathrm{~F}_{2}$ & 20.00 & 80.00 & 1.00 \\
$\mathrm{~F}_{3}$ & 30.00 & 70.00 & 2.00 \\
$\mathrm{~F}_{4}$ & 40.00 & 60.00 & 4.00 \\
\hline
\end{tabular}

\section{Evaluation of the lubricant emulsion}

\section{Lubricant emulsions stability against electrolytes}

The stability and resistance of the formulated lubricants against different sundry factors concerned in the leather processing for $10 \%$ lubricant aqueous emulsion of the differently formulated lubricant samples have been evaluated according to the method reported by Santos and Gutters [15]; three aqueous solutions of $5 \%$ $\mathrm{Cr}_{2}(\mathrm{SO} 4)_{3}, 5 \% \mathrm{Mg}\left(\mathrm{SO}_{4}\right)$, and $5 \% \mathrm{NaCl}$ with $1.5 \%$ $\mathrm{H}_{2} \mathrm{SO}_{4}$ have been prepared. The effect of the three solutions on the lubricant emulsion represents the different challenges acting on the lubricant emulsion during its operation. The lubricating process can be carried out during retanning or in hard water conditions. The first solution represents the attack or the negative effect of tan liquor, the second represents the reverse effect of the hard water. The last one represents the pickling conditions. About $3 \mathrm{ml}$ of each solution has been individually taken and completely mixed with 20 $\mathrm{ml}$ of $10 \%$ aqueous lubricant concentration. The appearance of the solution has been well observed over four hours duration of time. The aspects and degree of stability as milky, homogeneous, nonhomogeneous, or oil separation of the evaluated emulsions have been evaluated.

Lubricant emulsions stability towards $p H$ variation

The lubricant emulsion has been tested at alkaline and acidic conditions. At first, $10 \%$ aqueous emulsion concentration has been built as pale yellow to milky solution. For acid phase testing; $2 \mathrm{ml}$ formic acid was added to $20 \mathrm{ml}$ of $10 \%$ aqueous emulsion of the evaluated lubricants. For basic medium testing; $2 \mathrm{~g}$ sodium bicarbonate was added to $20 \mathrm{ml}$ of the emulsion. The emulsions were shaken until complete mixing and their aspects as homogenous, non-homogenous or oil separation have been observed over thirty minutes period of time [16].

Leather lubricating process

The process was carried out in a stainless steel reactor with stirring bars to be a substitute or similar to the drum. The wet blue leather samples were cut into small pieces of $5 \times 10 \mathrm{Cm}^{2}$ areas. The samples were cleaned through soaking in fresh water for $20 \mathrm{~min}$. The rinse water was discharged and the specimens were neutralized by $1.5 \%$ $\mathrm{CH} 3 \mathrm{COONa}$ ( based on the weight of the samples) followed by $0.75 \% \mathrm{Na}_{2} \mathrm{CO}_{3}$ in situ until greenish blue with bromo cresol green through the whole thickness ( $\mathrm{pH} 5.0$ - 5.5). After that, the lubricated process has been individually achieved using lubricants $\mathrm{F}_{3}$ and $\mathrm{F}_{4}$ at a fixed temperature of $55^{\circ} \mathrm{C}$ and agitation time of one hour. The concentrations of the lubricant emulsions of the $\mathrm{F}_{3}$ and $\mathrm{F}_{4}$ has been varied ( $2-10 \%$, based on the weight of the goods), so the performance of the two liquors under different emulsion concentration has been investigated. After the liquoring emulsion was discharged out,the specimens were rewashed with the suitable amount of water for the appropriate time (15 min.). The samples were hanged up in the open air at ambient temperature until complete drying and directed to the investigation.

\section{Testing the suitability of the lubricated leather}

The amount of fatty matter inserted into lubricated leather fibers (total fatty matter added) has been evaluated through stamp's method [17]; about $10 \mathrm{~g}$ of lubricated leather sample was finely cut into very small pieces and their weight was accurately recorded. The pieces were discharged into a soxhlet apparatus and extracted with a blend of 13 parts of methanol and 87 parts of chloroform $(\mathrm{v} / \mathrm{v})$ for six hours. The solvent was then evaporated and the fatty matter was calculated as \% percentage of weigh of samples. Tensile strength and elongation at break \% were measured using zwick-1425. Visible aspects of the lubricated sample have been spotted. The scanning electron microscopic investigation of the lubricated leather has been achieved using Jeol scanning microscope (Japan) JSM-T20 (sputter coater-Edwards-Model S-150 A, Eng.).

\section{Results and Discussion}

\section{Recovered neatsfoot oil characterization}

The crude recovered oil was separated as low viscous yellow color. The amount of the oil that was recovered from $5 \mathrm{~kg}$ bone legs and feet was approx. $527 \mathrm{~g}$, so the ratio of the recovered oil reaches to $10 \%$. The chemical properties of the oil have been illustrated in Table 2 .

The analytical data of the oil in the table are consistent with the general neatsfoot oil properties 
[18]. So the data confirm the possibility of the employment of the oil as leather lubricant agent. The relative decline in the iodine value and the relative increase in moisture and ash content are attributed to the fact that the oil is in its crude state without extra purification. The significant raise in a number of unsaponified materials and the relative decrease in saponification value can be interpreted for the same reason. In addition, the raise in the acid value can be explained by the fact that, some triglycerides undergo hydrolysis under the elevated temperature during the oil recovery and boiling the soup. This fact is in line with the fact approved by Izaki et al [19]. Saponification value and unsaponified matter are located at the standard level for oil analysis

TABLE 2. Chemical properties of recovered neats foot oil.

\begin{tabular}{lc}
\hline \multicolumn{1}{c}{ property } & Value \\
\hline Colour & Pale yellow \\
Moisture $\%$ & 3.92 \\
Ash $\%$ & 4.76 \\
Iodine value $\mathrm{mg} \mathrm{I}_{2} / \mathrm{g}$ oil & $66.80^{\circ} \mathrm{C}$ \\
Acid value $\mathrm{mg} \mathrm{KOH} / \mathrm{g}$ oil & 14.00 \\
Free fatty acid $\%$ & 7.00 \\
Saponification value $\mathrm{mg} \mathrm{KOH} / \mathrm{g}$ oil & 177.00 \\
Unsaponified matter & 4.61 \\
\hline
\end{tabular}

Constancy testing of the lubricating emulsions

The lubricant may be held in the drum through the leather manufacturing in presence of some electrolytes or at low $\mathrm{pH}$ value. The lubricant emulsion has to oppose these factors and be steady until complete process without precipitation or oil separation. The lubricant emulsion stability towards the different electrolytes and $\mathrm{pH}$ variation of the $10 \%$ concentration of the differently formulated lubricants has been illustrated in Tables 3 and 4 .

The data revealed that, the emulsions of lubricants with low content of oil and anionic emulsifier exert weak resistance against electrolytes and $\mathrm{pH}$ variation. The lubricants $\mathrm{F}_{1}$ and $\mathrm{F}_{2}$ show oil separation. So they are not eligible for the overhead lubricating process. The lubricants $\mathrm{F} 3$ and $\mathrm{F}_{4}$ bring to bear strong resistance in opposition to the electrolytes and $\mathrm{pH}$ at the same condition for longer period of time. It is well known that the time required for achieving the lubricating process is approximately one hour [9]. Accordingly, the time duration stability of the emulsions of $F_{1}$ and $F_{2}$ does not realize the purpose, as their emulsions show no homogeneity and oil separation. So they are completely excluded. On the other hand, the emulsions of $F_{3}$ and $F_{4}$ show stability up to three hours showing homogeneity and preferred milky appearance.

TABLE 3 . Stability of formulated lubricants against different.

\begin{tabular}{|c|c|c|c|c|c|}
\hline \multirow{2}{*}{ Factor } & \multicolumn{5}{|c|}{$\begin{array}{c}\text { Stability of the } 10 \% \text { aqueous emulsion of formulated } \\
\text { fatliquor after two hours }\end{array}$} \\
\hline & $\mathrm{F}_{1}$ & $\mathbf{F}_{2}$ & $\mathbf{F}_{3}$ & $\mathbf{F}_{4}$ & Cf \\
\hline $5 \% \mathrm{Cr}_{2}\left(\mathrm{SO}_{4}\right)_{3}[\tan$ liquor $]$ & $\mathrm{O} \mathrm{S}^{*}$ & $\mathrm{NH}^{*}$ & $\mathrm{H}^{*}$ & $\mathrm{H}^{*}$ & $\mathrm{H}$ \\
\hline $5 \% \mathrm{Mg}\left(\mathrm{SO}_{4}\right)$ [hard water $]$ & OS & $\mathrm{NH}$ & $\mathrm{H}$ & $\mathrm{H}$ & $\mathrm{H}$ \\
\hline $5 \% \mathrm{NaCl}$ with $1.5 \% \mathrm{H}_{2} \mathrm{SO}_{4}$ [pickle liquor] & OS & NH & $\mathrm{H}$ & $\mathrm{H}$ & $\mathrm{H}$ \\
\hline
\end{tabular}

* O S oil separation, NH non-homogeneous, H milky and homogeneous - ** CL commercial lubricant

TABLE 4.Stability of formulated fatliquors in different mediums.

\begin{tabular}{cccc}
\hline \multirow{2}{*}{ fatliquor } & & pH & \\
\cline { 2 - 4 } & neutral & acidic & basic \\
\hline $\mathrm{F}_{1}$ & $\mathrm{H}$ & $\mathrm{NH}$ & $\mathrm{NH}$ \\
$\mathrm{F}_{2}$ & $\mathrm{H}$ & $\mathrm{H}$ & $\mathrm{NH}$ \\
$\mathrm{F}_{3}$ & $\mathrm{H}$ & $\mathrm{H}$ & $\mathrm{H}$ \\
$\mathrm{F}_{4}$ & $\mathrm{H}$ & $\mathrm{H}$ & $\mathrm{H}$ \\
$\mathrm{CL}^{* *}$ & $\mathrm{H}$ & $\mathrm{H}$ & $\mathrm{H}$
\end{tabular}


Assessment of the lubricated leather

Figure 1 shows the relation between integrated oil into leather fibers and lubricant emulsion concentration $\%$. The data in the figure show that the high concentrated emulsions were able to add more fatty matter to leather fibers and the total amount of incorporated oil is proportional to emulsion concentration.

The regular increase in incorporated oil parallel to concentration of lubricant emulsion, verify that the newly- incorporated oil comes from the emulsion and the oil is capable to coat the leather fibers, causing mechanical properties enhancement of lubricated leather [8]. The lubricant emulsions of $\mathrm{F}_{4}$ were able to add large amounts of oil compared with $F_{3}$. However, each of them was able to add the desired amount of oil at high lubricant emulsion concentration. On the other hand, the lubricant was able to incorporate oil proximate to that was added by commercial lubricant at the same concentration. The development of the tensile strength and elongation at break \% parallel to different lubricant emulsion concentration (2-10\%) of F3 and $\mathrm{F}_{4}$ liquors are illustrated in Fig. 2 \& 3.

The data in the figures show that the tensile strength and elongation at break \% increase as the emulsions concentration increases. The desired mechanical properties enhancement of all lubricants $\mathrm{F}_{3}, \mathrm{~F}_{4}$, and $\mathrm{CL}$ (commercial lubricant) has been recognized at $10 \%$ emulsion concentration. However, the improvement caused by $\mathrm{F}_{1}$ and $\mathrm{F}_{2}$ remains less than that experienced by the commercial lubricant (CL). In addition, the data in figures revealed that the liquoring effect of $\mathrm{F}_{4}$ is greater than $\mathrm{F}_{3}$. However, the required

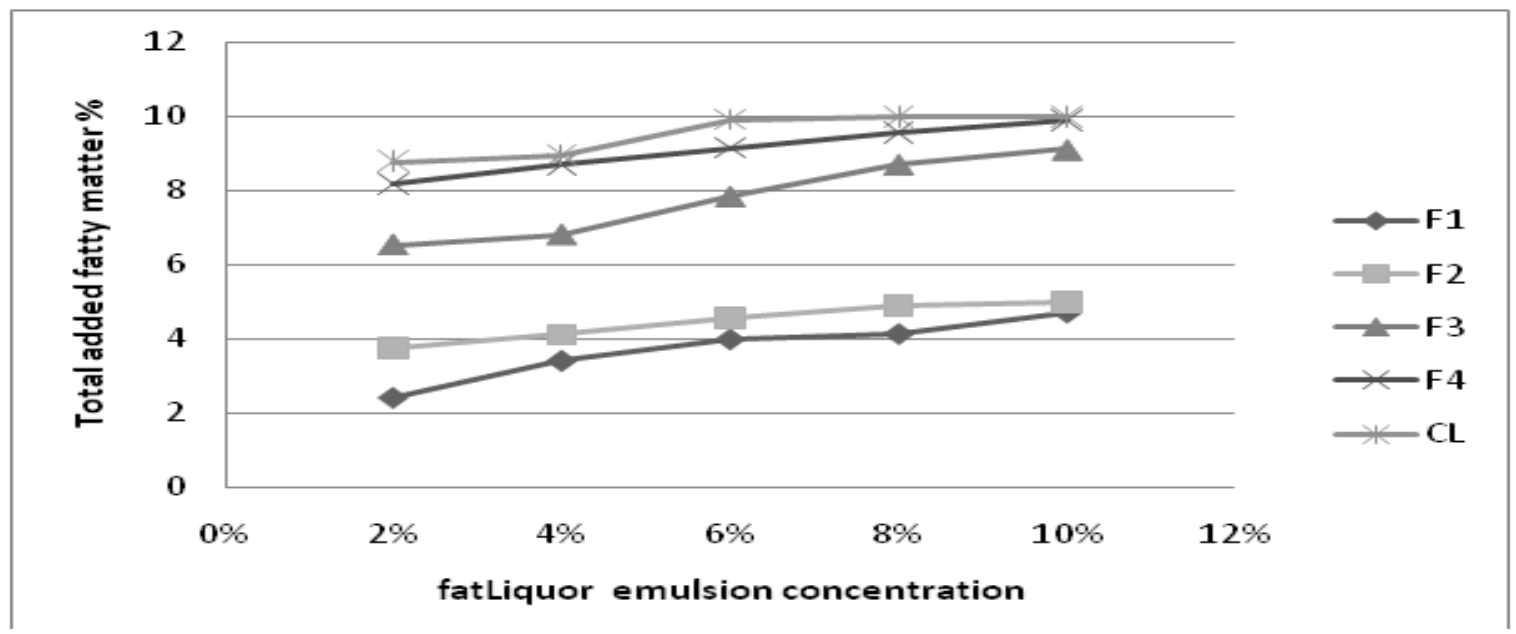

Fig.1. Total fatty matter added to lubricated leather by different lubricants at different emulsion concentrations.

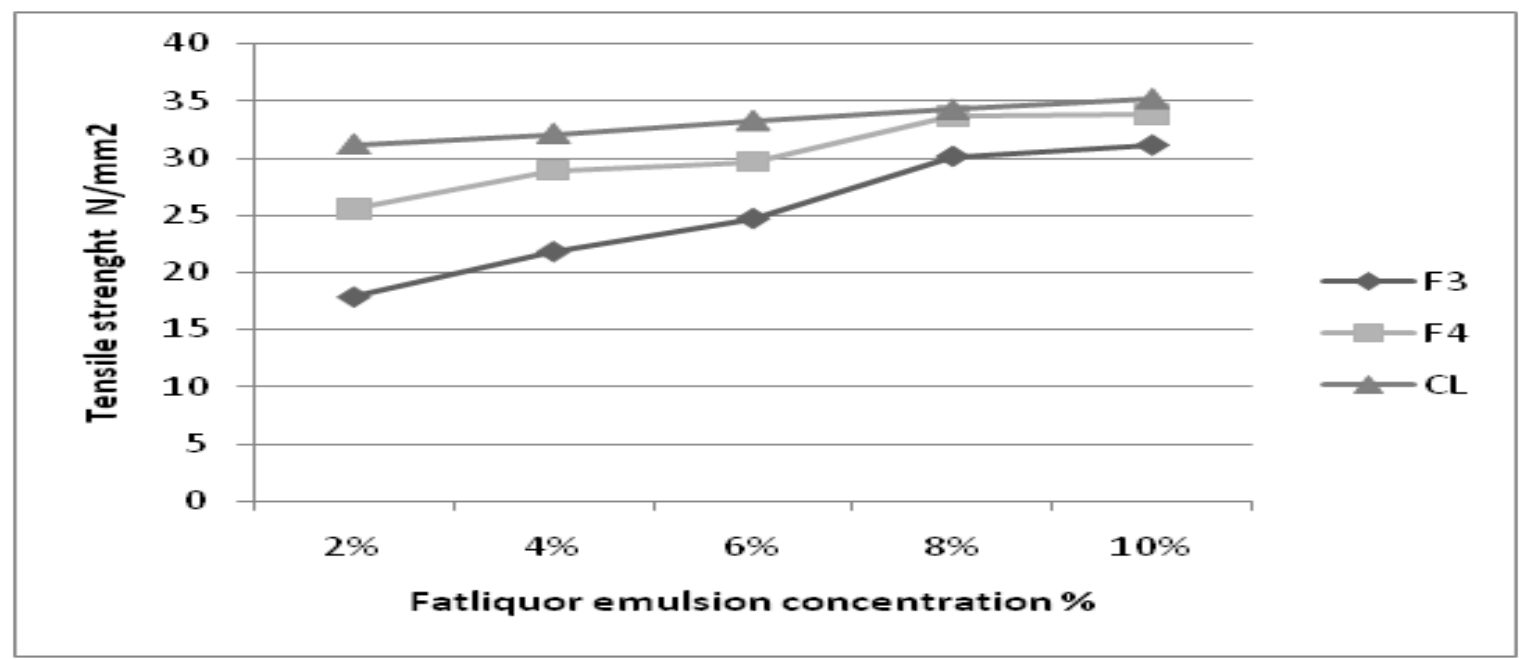

Fig. 2. Tensile strength of lubricated leather at different emulsion concentrations. 


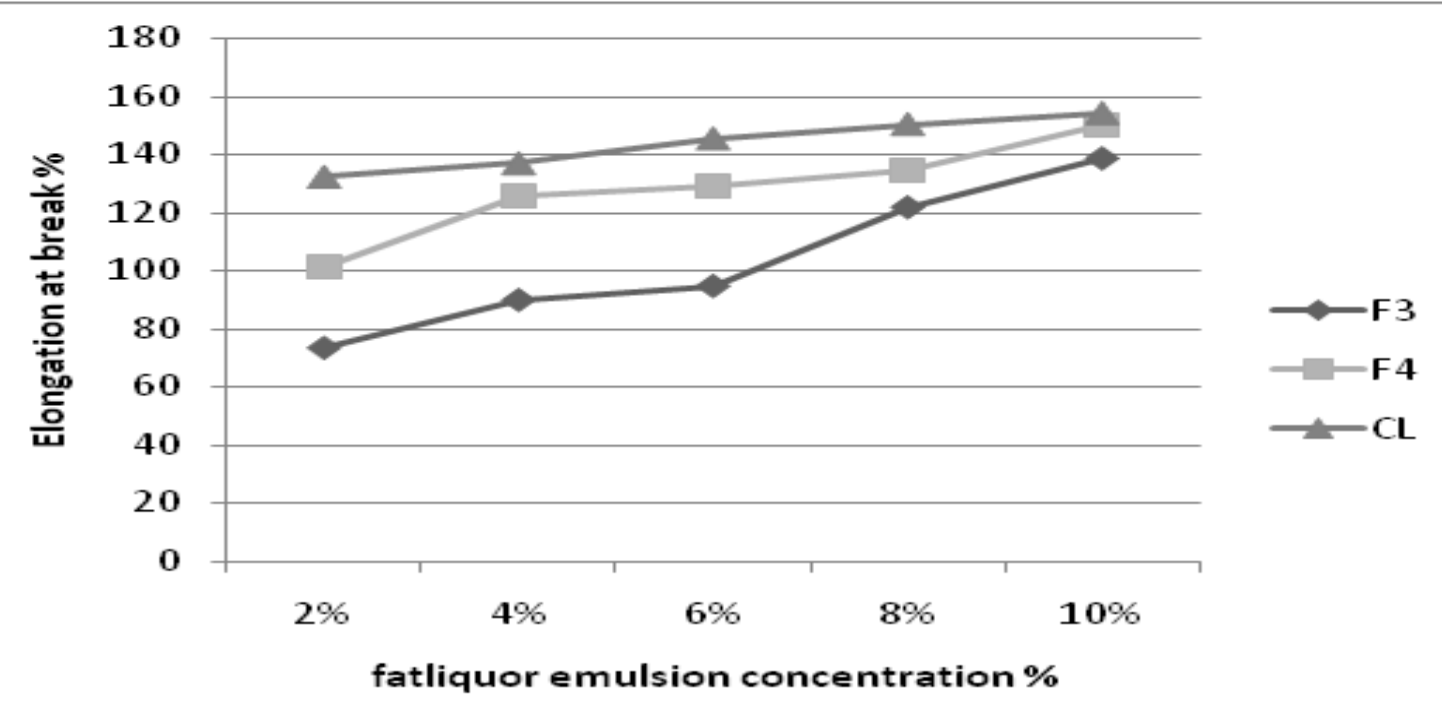

Fig. 3. Elongation at break of lubricated leather at different emulsion concentrations

mechanical properties enhancement has been reached in case of lubricating with both $\mathrm{F}_{3}$ and $\mathrm{F}_{4}$. Figures 2 and 3 show ongoing increase in tensile strength and elongation at break $\%$ follows the increase of the emulsion concentrations, signifying that the oil was able imparting a mass to leather. As a result, special functions such as higher pliability, waterproof, light fastness, flexibility capabilities, perspiration resistance are enhanced [20]. Figure 4 shows the surface of the leather sample before and after lubrication.

The figures show great leather surface enhancement after lubrication, signifying the coating of the leather fibers and weighting of the surface, as a result, the leather tissues are fine coated.

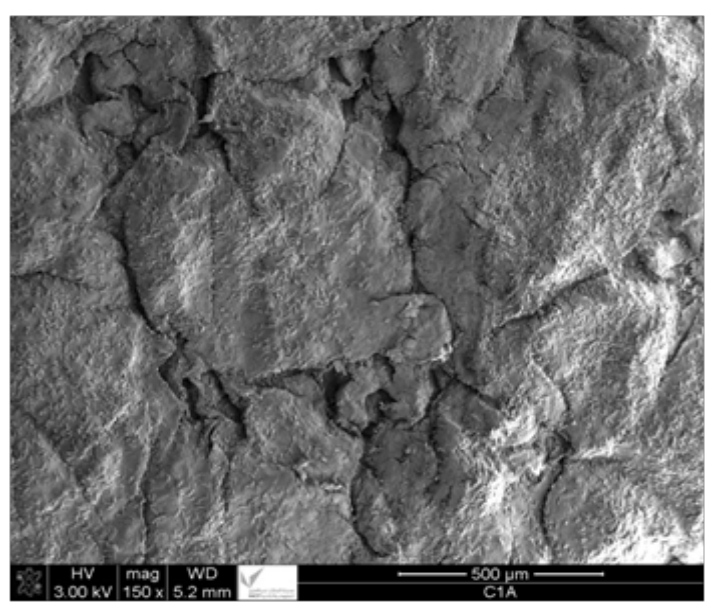

Before lubricating

\section{Conclusion}

Neatsfoot oil has been recovered from massacres byproducts through a low-cost pathway. Leather lubricant with acceptable lubricating effect has been formulated from the recovered oil without chemical modification or further chemical reaction. The lubricant emulsion exerts good emulsion stability and resistance towards, hard water, metallic ions and $\mathrm{pH}$ variation. The lubricant was able to add filling material close to that incorporated by the commercial lubricant emulsion. The formulated lubricant and the commercial one performed the same improvement in mechanical properties almost at high lubricant emulsion concentration.

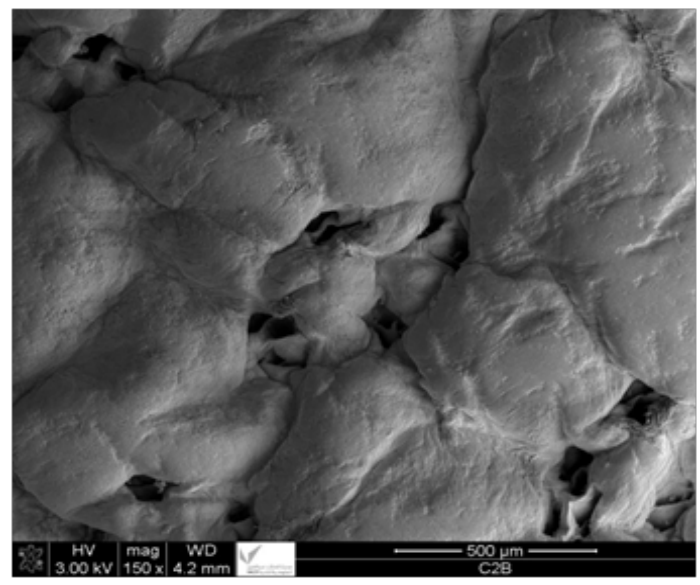

After lubricating

Fig. 4. Scanning electron microscope (X500) of the leather samples before and after lubricating

Egypt. J. Chem. 60, No. 4 (2017) 


\section{References}

1. Rick Arneil, D. Arancon, Carol Sze Ki Lin, King Ming Chan, Tsz Him Kwan and Rafael Luque., Advances on waste valorization: new horizons for a more sustainable society, Energy Science and Engineering, 1, 53 (2013).

2. Anil, M. H., McKinstry, J. L., Field, M. and Rodway, R.G ., Lack of evidence for stress being caused to pigs by witnessing the slaughter of conspecifics, Animal Welfare, 6, 3 (1997).

3. Jayathilakan, K., Khudsia Sultana, Radhakrishna, K. and Bawa, A.S., Utilization of byproducts and waste materials from meat, poultry and fish processing industries: a review , J Food Sci Technol., 49, 278 (2012)

4. Russ, W. and Pittroff, R.M., Utilizing waste products from the food production and processing industries.,Crit Rev Food SciNutr. 44, 57 (2004).

5. West, G. C. and Shaw, D. L., Fatty acid composition of dall sheep bone marrow, Comp BiochemPhysiol B., 50, 599 (1975).

6. Alexander, G., Stevens, D. and Bradley, L. R., Fostering in she ep: experiences with the use of neatsfoot oil, Aust J Exp Agric. 27, 771 (1987).

7. Mohamed, O.A., Habib, M.A. and El Sayed, N.H., Production of leather fat liquoring agents from local sources as alternative for imported liquors, Egypt $J$. Chem. 52, 507 (2009).

8. Kaussen, M., Fatliquoring Agent for Improving Properties of Furniture and Automotive Leather., $J$. Am. Leather Chem. Assoc, 93, 16 (1998).

9. Habib, M. A. and Alshammari, A. G., Leather fatliquor from hide flestings., J. Soc. Leath Tech. Ch, 98, 5, 199 (2014).

10. Qing, S. F. and Tang, K.Y., Studty on the technology of high grade fat-liquoring agent from modified cottonseed oil, China Leather, 34, 40 (2005).

11. Jan Zarlok, Krzysztof Smiechowski, KatarzynaMucha and AgnieszkaTecza , Research on application of flax and soya oil for leather fatliquoring., J. Clean Prod. 65, 583 (2013).

12. Nyamunda, B. C., Moyo, M. and Chigondo, F., Synthesis of fatliquor from waste bovine fat for use in small scale leather industry., Indian Journal of Chemical Technology, 20,116 (2013).

13. A.O.C.S. Official and Tentative Methods for the American Oil Chemist's Society. 6 and 7th ed.
American Oil Chemist's Society, Champaign, U.S.A. (1993 and 1997).

14. Firestone, D.,Physical and Chemical Characteristics of Oils, Fats and Waxes, AOCS Press, Washington, DC. (1999).

15. Santos, L.M. and Gutterres, M., Reusing of a hide waste for leather fatliquoring, J. Clean. Prod, 15, 12 (2007).

16. Cuq, M. H., Benjelloun-Mlayah, B. and Delmas M., Oil extracted from seal hides: Characterization and use as leather fat liquor. , JAOCS, 75 ,1015 (1998).

17. Stamp, D. H., J. Am. Leather Chem. Ass.7, 290 (1974).

18. Indian standard specification for neats foot oil (Incorporating Amendment No.1) UDe 665 .218, third reprint september 1999.

19. Izaki ,Y. , Yoshikawa, S. and Uchiyama, M., Effect of ingestion of thermally oxidized frying oil on peroxidative criteria in rats, Lipids, 19, 324 (1984).

20. Lio, L.L. and Shan, Z.H., Leather Chemical and Technology, Science Publishing Company: Beijing. 2005.

(Received: 25 / 5 /2017; accepted: 13 / 8 /2017) 


\section{استخدامزيت حوافر البقر المسترجع كمادة اولية في تصنيع الجلود الطبيعية وتوظيفة كمادة تثحيم غير معدلة كيميائيا}

محمد احمد حبيب

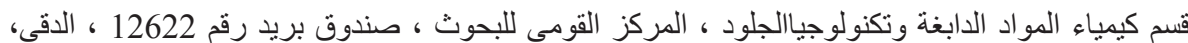

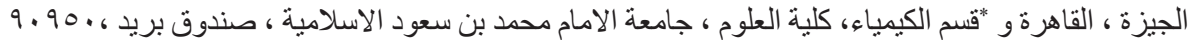

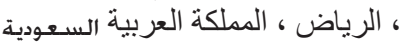

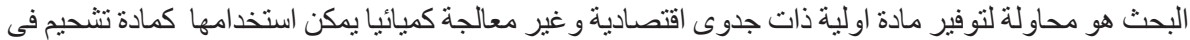

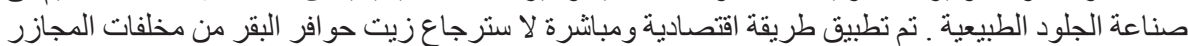

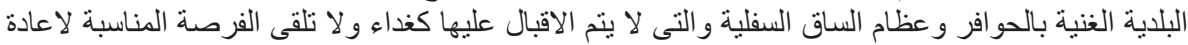

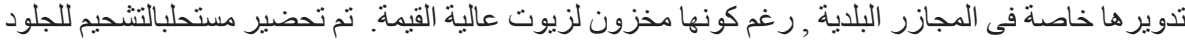

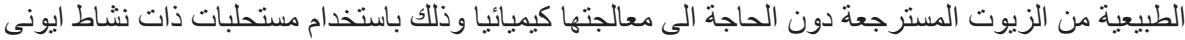

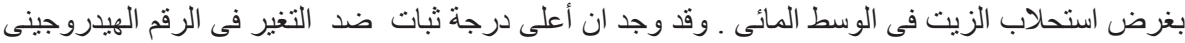

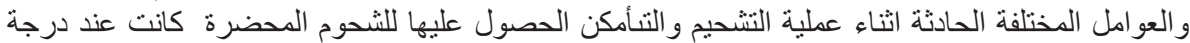

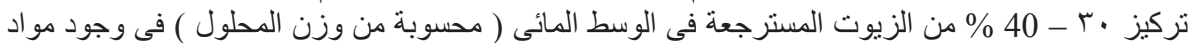

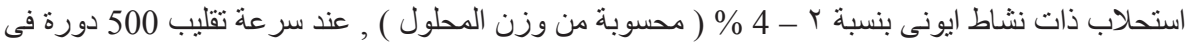

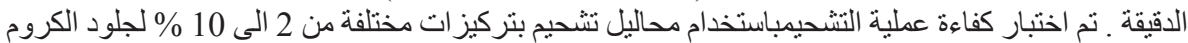

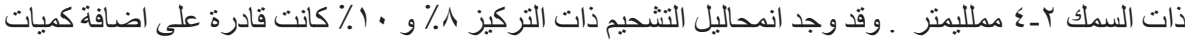
الزيوت اللازمة لاتمام عملية النشحيم بنجاح , حيث كانت نسب الزيوت

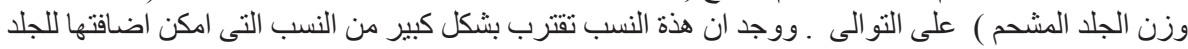

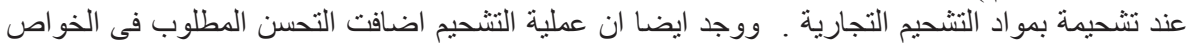

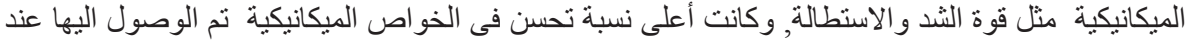

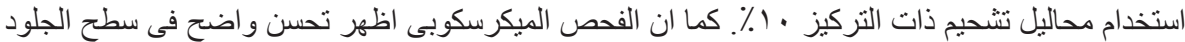

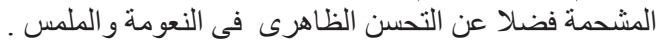

